\title{
Sleep Abnormalities in Progressive Supranuclear Palsy
}

\author{
Michael S. Aldrich, MD, ${ }^{*}$ Norman L. Foster, MD,* Roberta F. White, PhD, $+\neq$ Laurie Bluemlein, MS, RN,* \\ and Gregory Prokopowicz, BA*
}

\begin{abstract}
We studied sleep patterns for three nights in 10 subjects with moderate to severe progressive supranuclear palsy and correlated the findings with disease severity using quantitative measures of motor, cognitive, and eye movement impairment. All subjects had severe insomnia, spending 2 to 6 hours awake per night; the mean time awake per night for the group was more than 4 hours. Sleep latency became shorter and the number of awakenings increased with greater motor impairment, and total sleep time declined as dementia worsened. These findings indicate that in progressive supranuclear palsy insomnia is related to disease severity. Insomnia associated with progressive supranuclear palsy appears to be worse than the insomnia of Parkinson's disease or Alzheimer's disease and may be due to degenerative changes in brain structures responsible for sleep maintenance.
\end{abstract}

Aldrich MS, Foster NL, White RF, Bluemlein L, Prokopowicz G. Sleep abnormalities in progressive supranuclear palsy. Ann Neurol 1989;25:577-581

Progressive supranuclear palsy (PSP) is a degenerative neurological disorder characterized by impaired voluntary gaze, axial rigidity, and dementia. Sleep complaints are common, and sleep studies have shown prolonged sleep latency, impaired sleep continuity, decreased or absent sleep spindles [1,2], and reduced amounts of rapid eye movement (REM) sleep [3].

Sleep disturbance in PSP could be due to degenerative neurochemical or neuropathological changes affecting areas of the brain involved with sleep regulation. If so, sleep disturbances should increase as the disease worsens. In support of this hypothesis, Perret and Jouvet [3] found that 2 patients with severe clinical impairment had greater sleep disturbance than did 7 patients with milder disease. In this study we sought to test this hypothesis further and, if we found confirmatory evidence that sleep disturbance correlated with clinical disease severity, to determine which specific aspects of clinical impairment correlated with sleep abnormalities.

\section{Methods}

Ten patients ( 6 women and 4 men whose mean age was 67 years; range 60-74) with clinically diagnosed PSP were included in the study. The patients, who were studied during the placebo phase of a drug trial for treatment of PSP [4], were rigorously evaluated to exclude other possible causes of dementia and rigidity. Their motor impairment ranged from mild (some difficulty with ambulation) to profound (bedrid- den and immobile). All subjects had dementia by criteria outlined in the Diagnostic and Statistical Manual of Mental Disorders [5], with mild to moderate cognitive impairment (mean full-scale intelligence quotient 86 [range $75-101$ ] by the Wechsler Adult Intelligence Scale-Revised). None were clinically depressed.

Other than having PSP, the subjects were generally healthy at the time of the study. With the exception of glycopyrrolate (an anticholinergic agent that does not penetrate to the central nervous system), all medications, including sedatives and dopaminergic medications, had been discontinued 3 weeks prior to the study.

Subjects were admitted to the University of Michigan Clinical Research Center and underwent three sleep recordings. The recordings were scheduled from 10:30 PM to 6:30 AM on consecutive nights, but they were started up to 1 hour earlier or later, depending on the sleep habits of the subjects. For each sleep study, surface electrodes were applied to record the electroencephalogram, electrooculogram, submental electromyogram, and electrocardiogram. During the first night, 8 of the 10 subjects were also monitored for nasal-oral airflow, respiratory effort, blood oxygen saturation, and leg movements.

The first night was viewed as an adaptation night, and the presence of periodic leg movements and sleep apnea were assessed. Sleep studies from the second and third nights were scored for sleep stages using conventional scoring criteria applied to each 30-second epoch of recording [6]. All scoring was done by registered polysomnographic technologists and reviewed by an accredited clinical polysomnographer (M.S.A.).
From the Departments of *Neurology and $\nmid$ Psychiatry, University of Michigan Medical Center, Ann Arbor, MI.

Received Sep 2, 1988, and in revised form Nov 4. Accepted for publication Dec 3, 1988.
Address correspondence to Dr Aldrich, Department of Neurology, 1920/0316 Taubman Center, 1500 East Medical Center Drive, University of Michigan Medical Center, Ann Arbor, MI 48109-0316.

$\ddagger$ Present address: Boston Veterans Administration Medical Center, Boston, MA. 
We defined sleep latency as the time from lights out to the first epoch of any stage of sleep. Persistent sleep was defined as 5 minutes or more of continuous sleep. REM sleep latency was defined as the length of time from sleep onset to the first epoch of REM sleep. Sleep efficiency was defined as the proportion of time spent asleep from sleep onset to the final awakening.

Motor function and voluntary eye movements were assessed independently by two observers (M.S.A., L.B.). A Motor Rating Scale was used to assess facial expression, speech, handwriting, postural stability, gait, balance, fine movements of the hands, and axial and limb rigidity [4]. Each feature was rated from 0 (no abnormality) to 4 (severe impairment). Voluntary eye movements were assessed by visual estimation of the degrees of ocular rotation in each of four directions (up, down, left, right). To control for day-to-day variability, the Motor Rating Scale and eye movement scores were determined serially for each subject three times during the week of the sleep studies and once weekly for the next 4 weeks.

Neuropsychological function was assessed using the following tests: Wechsler Adult Intelligence Scale-Revised, Mini-Mental State [7], Buschke Selective Reminding Task [8], Boston Diagnostic Aphasia Examination [9], Profile of Moods States [10], and Verbal Fluency examination [11]. Since some subjects were unable to complete all parts of the Mini-Mental State examination because of motor or speech impairment, the Mini-Mental State score was expressed as a fraction of the best possible score.

The results of polysomnographic analysis were compared to published values for normal men aged 60 to 69 [12] using Student's $t$ test. We correlated polysomnographic results with clinical variables and performed regression analysis on significant correlations (Statgraphics Statistical Graphics System, Statistical Graphics Corporation, 1985).

\section{Results}

The results of the sleep studies are summarized in Table 1, and clinical and neuropsychometric assessments are shown in Table 2 . Two representative sleep studies are illustrated in Figure 1. No subject spent less than 2 hours awake per night. Latencies to sleep and to REM sleep were highly variable; 4 of the subjects had REM latencies of less than 10 minutes on one or both of the recording nights.

Two subjects had sleep apnea and periodic leg movements. In 1 apnea was mainly central, and in the other it was predominantly obstructive (apneas plus hypopneas per hour of sleep were 34 and 60 , respectively, for the 2 subjects). Periodic leg movements per hour of sleep were 21 and 28, respectively. We calculated mean values for polysomnographic variables in

Table 1. Polysomnograpbic Results

\begin{tabular}{|c|c|c|c|c|c|c|}
\hline \multirow[b]{2}{*}{ Characteristic } & \multicolumn{3}{|c|}{ PSP Subjects } & \multicolumn{2}{|c|}{$\begin{array}{l}\text { Published } \\
\text { Norms [12] }\end{array}$} & \multirow[b]{2}{*}{$p^{\mathrm{a}}$} \\
\hline & Mean & $\mathrm{SD}$ & Range & Mean & $\mathrm{SD}$ & \\
\hline Time awake (min) & 245.0 & 60.9 & $127-352$ & 44.3 & 43.2 & $<0.02$ \\
\hline Time asleep (min) & 233.8 & 52.2 & $163-348$ & 407.3 & 44.6 & $<0.05$ \\
\hline Sleep efficiency $(\%)$ & 58.1 & 10.9 & $44-80$ & 90.0 & 7.0 & $<0.05$ \\
\hline Percent wakefulness & 50.8 & 11.6 & $27-68$ & 9.8 & 6.0 & $<0.01$ \\
\hline Percent stage 1 sleep & 15.9 & 5.9 & $9-27$ & 9.5 & 4.0 & \\
\hline Percent stage 2 sleep & 22.1 & 8.3 & $8-35$ & 55.5 & 8.8 & $<0.05$ \\
\hline Percent stage $3-4$ sleep & 4.1 & 2.8 & $0-10$ & 2.6 & 5.0 & \\
\hline Percent REM sleep & 6.8 & 2.8 & $2-13$ & 22.6 & 3.6 & $<0.01$ \\
\hline Latency to sleep (min) & 28.1 & 15.6 & $8-58$ & 8.3 & 10.5 & \\
\hline Latency to persistent sleep (min) & 66.4 & 61.8 & $19-239$ & & & \\
\hline Latency to stage 2 sleep (min) & 49.4 & 25.9 & $7-100$ & 16.7 & 12.4 & \\
\hline REM latency (min) & 80.3 & 57.7 & $9-188$ & 83.9 & 38.1 & \\
\hline No. of REM periods & 3.5 & 1.2 & $1-6$ & 4.5 & 0.7 & \\
\hline Average REM period duration (min) & 9.5 & 3.1 & $6-15$ & 23.2 & 5.0 & $<0.05$ \\
\hline Wake after sleep (min) & 9.6 & 12.1 & $0-38$ & & & \\
\hline Wake during sleep (min) & 172.7 & 49.0 & $88-247$ & 34.0 & & $<0.02$ \\
\hline No. of awakenings & 33.3 & 16.7 & $10-69$ & 7.5 & 3.7 & \\
\hline No. of awakenings $>2 \mathrm{~min}$ & 13.8 & 5.4 & $4-23$ & & & \\
\hline
\end{tabular}

${ }^{2}$ Significant differences from published norms all remained statistically significant when the 2 patients with sleep apnea and periodic leg movements were excluded.

$\mathrm{SD}=$ standard deviation; REM = rapid eye movement; PSP = progressive supranuclear palsy. 
Table 2. Clinical and Neuropsychometric Assessments ${ }^{\mathbf{a}}$

\begin{tabular}{|c|c|c|c|c|}
\hline Studies & No. & Mean & SD & Range \\
\hline Motor Rating Scale score & 10 & 37.4 & 11.1 & $25-56$ \\
\hline \multicolumn{5}{|l|}{ Voluntary eye movements } \\
\hline Vertical degrees: up + down & 10 & 15.5 & 7.5 & $0-31$ \\
\hline Horizontal degrees: left + right & 10 & 85.3 & 33.3 & $1-117$ \\
\hline \multicolumn{5}{|l|}{ Neuropsychometric studies } \\
\hline Full-scale IQ & 8 & 85.6 & 7.5 & $75-101$ \\
\hline Memory quotient & 8 & 96.6 & 12.6 & $79-117$ \\
\hline Mini-Mental State & 8 & 0.81 & 0.11 & $0.7-1.0$ \\
\hline Profile of Moods States & 7 & 43.8 & 12.9 & $32-69$ \\
\hline Verbal Fluency & 9 & 6.6 & 5.9 & $1-17$ \\
\hline $\begin{array}{l}\text { Boston Diagnostic Aphasia Examination Subtest: } \\
\text { Complex Ideational Material }\end{array}$ & 10 & 9.4 & 1.6 & $7-12$ \\
\hline Buschke Selective Reminding Task & 9 & 16.8 & 16.0 & $0-46$ \\
\hline Subtest: Intrusions & 9 & 0.4 & 0.4 & $0-1.3$ \\
\hline Subtest: Hits & 10 & 8.9 & 1.1 & $6-10$ \\
\hline Subtest: False Alarms & 10 & 0.6 & 0.8 & $0-3$ \\
\hline
\end{tabular}

${ }^{\text {aS }}$ Some subjects were unable to complete all of the tests because of motor or speech disturbance.

$\mathrm{IQ}=$ intelligence quotient; $\mathrm{SD}=$ standard deviation.

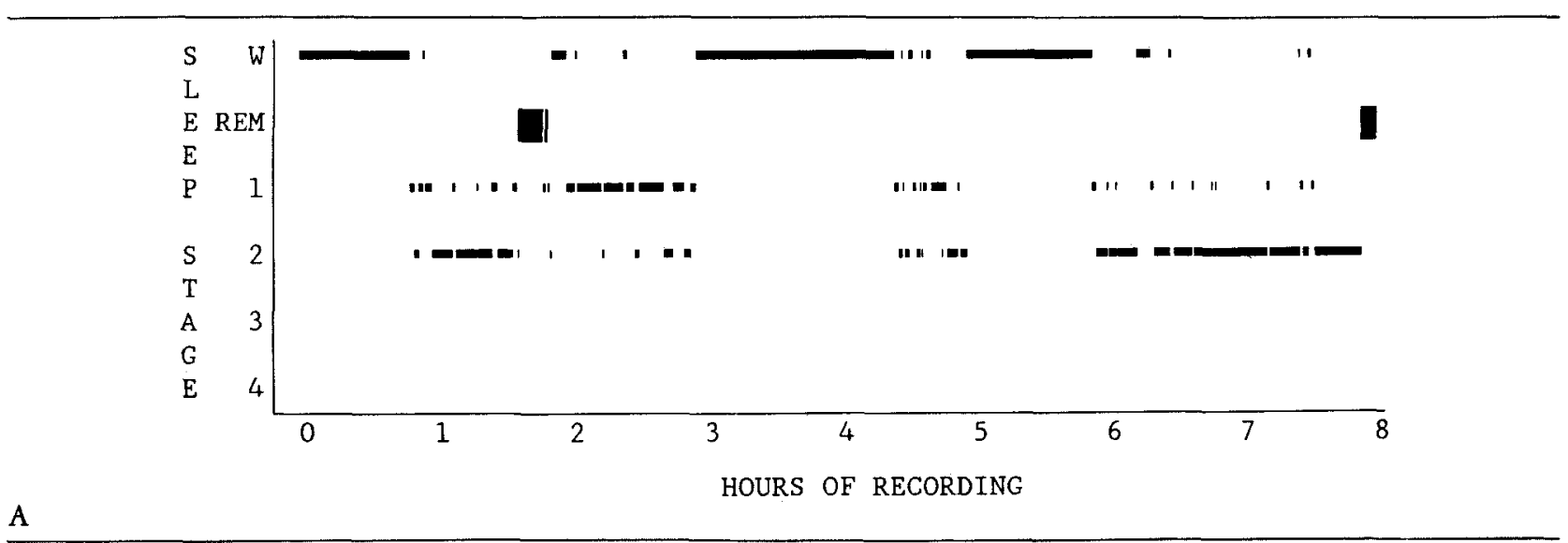

A

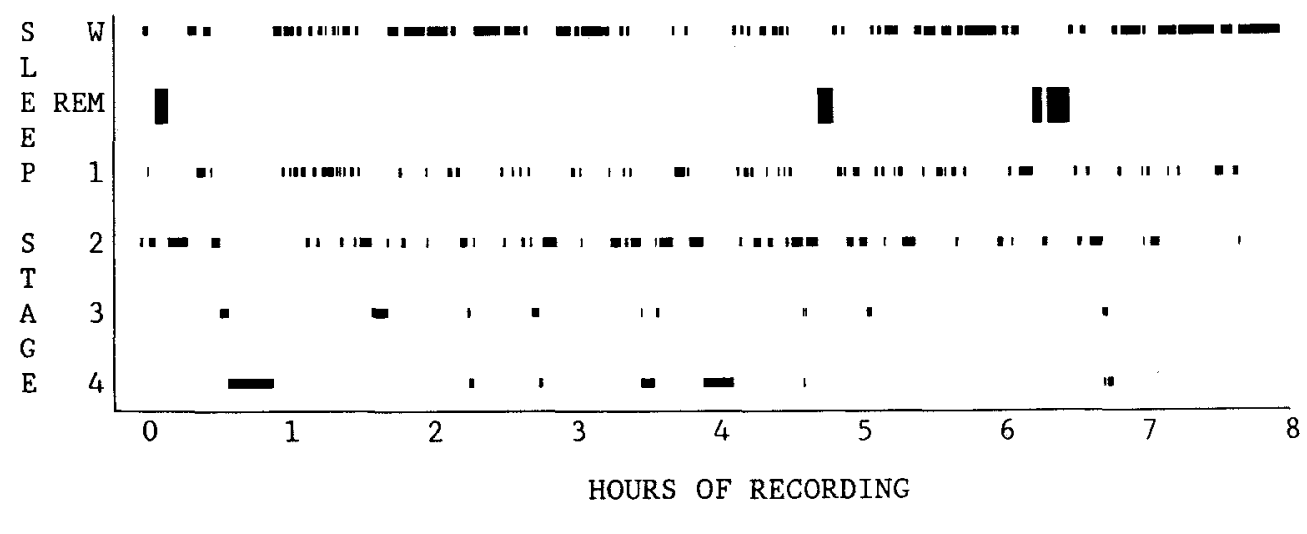

B

Fig 1. Two representative polysomnograms. (A) The top panel is a recording from a 72-year-old man with progressive supranuclear palsy of moderate severity (Motor Rating Scale $=26$ ). Long sleep latency and two long awakenings account for most of the time awake. (B) The lower panel is a recording from a 67-yearold woman with severe progressive supranuclear palsy (Motor Rating Scale $=56$ ). There is severe sleep fragmentation, with more than 62 awakenings. 
Table 3. Correlation of Sleep Variables with Selected Clinical Scales ${ }^{a}$

\begin{tabular}{|c|c|c|c|c|c|c|c|c|c|c|c|}
\hline \multirow[b]{3}{*}{ Characteristic } & \multirow{3}{*}{$\begin{array}{l}\text { Total } \\
\text { Motor } \\
\text { Rating } \\
\text { Scale }\end{array}$} & \multirow{2}{*}{\multicolumn{5}{|c|}{ Motor Subscales }} & \multicolumn{5}{|c|}{ Neuropsychometrics } \\
\hline & & & & & & & \multirow{2}{*}{$\begin{array}{l}\text { Complex } \\
\text { Ideational } \\
\text { Material }\end{array}$} & \multirow[b]{2}{*}{$\begin{array}{l}\text { Profile } \\
\text { of Moods }\end{array}$} & \multirow{2}{*}{$\begin{array}{l}\text { Full- } \\
\text { Scale } \\
\text { IQ }\end{array}$} & \multirow[b]{2}{*}{$\begin{array}{l}\text { Memory } \\
\text { Quotient }\end{array}$} & \multirow{2}{*}{$\begin{array}{l}\text { Mini- } \\
\text { Mental } \\
\text { Status }\end{array}$} \\
\hline & & $\begin{array}{l}\text { Facial } \\
\text { Movement }\end{array}$ & Posture & Gait & $\begin{array}{l}\text { Finger } \\
\text { Dexterity }\end{array}$ & Rigidity & & & & & \\
\hline Total time awake & & & & & & & & .57 & & & $-.77^{*}$ \\
\hline Total time asleep & & & & & & & & -.63 & & & $.82^{*}$ \\
\hline $\begin{array}{l}\text { Minutes of stage } \\
3-4 \text { sleep }\end{array}$ & $.85^{* *}$ & $.77^{* *}$ & $.88^{* * * *}$ & $.95^{* * * *}$ & $.87^{* * * *}$ & $.79 * *$ & & & & & \\
\hline Latency to sleep & $-.78^{* *}$ & $-.67^{*}$ & -.58 & $-.66^{*}$ & $-.82^{* *}$ & $-.90^{* * *}$ & .59 & & & & \\
\hline Latency to REM sleep & & & & & & & & -.59 & & & \\
\hline Number of REM periods & & & & & & & & $.80^{*}$ & -.51 & -.66 & -.67 \\
\hline $\begin{array}{l}\text { Number of awakenings } \\
>2 \mathrm{~min}\end{array}$ & $.82^{* *}$ & $.73^{*}$ & .62 & $.77^{* *}$ & $.87^{* * *}$ & $.85^{* *}$ & $-.73^{*}$ & .50 & & -.50 & \\
\hline
\end{tabular}

${ }^{2}$ Correlations less than .50 are not shown.

${ }^{*} p<0.05$.

$* * p<0.01$

${ }_{* * * *} p<0.001$

$\mathrm{IQ}=$ intelligence quotient; $\mathrm{REM}=$ rapid eye movement.

the 8 subjects without sleep apnea or periodic leg movements and found that only number of awakenings and REM latency were more than $6 \%$ different from the group as a whole. The 2 apneic subjects had a mean REM latency of 33 minutes compared with a mean of 92 minutes in the other 8 subjects, and they had 62 awakenings per night compared with 26 for the other 8 .

Sleep spindles were poorly formed or absent in 5 subjects. Rapid eye movements during REM sleep were also reduced in 5 and appeared to be of low amplitude by subjective assessment. In the most impaired patients, scoring of sleep stages was difficult because of one or more of the following factors: reduced or absent eye movements during sleep that showed all other characteristics of REM sleep, poorly formed or absent sleep spindles and K-complexes, persistent electroencephalographic alpha activity during stage 1-2 sleep, and increased slow activity in the waking electroencephalogram.

Significant correlations of sleep variables with clinical scales are shown in Table 3. We performed the same correlational analysis excluding the 2 patients with sleep apnea and found that all correlations were similar and remained significant. Although sleep latency was longer than published norms for this age group, latency to sleep was inversely correlated with motor impairment. Overall motor impairment correlated with sleep fragmentation as measured by the number of awakenings (Fig 2), but it did not correlate with amount of time spent awake. Cognitive and eye movement abnormalities correlated positively with sleep disturbance, but the correlations were weaker than those between motor impairment and sleep disturbance.

While the mean amount of stage 3-4 sleep was reduced in the PSP subjects as compared with published norms, the amount of stage 3-4 sleep increased with

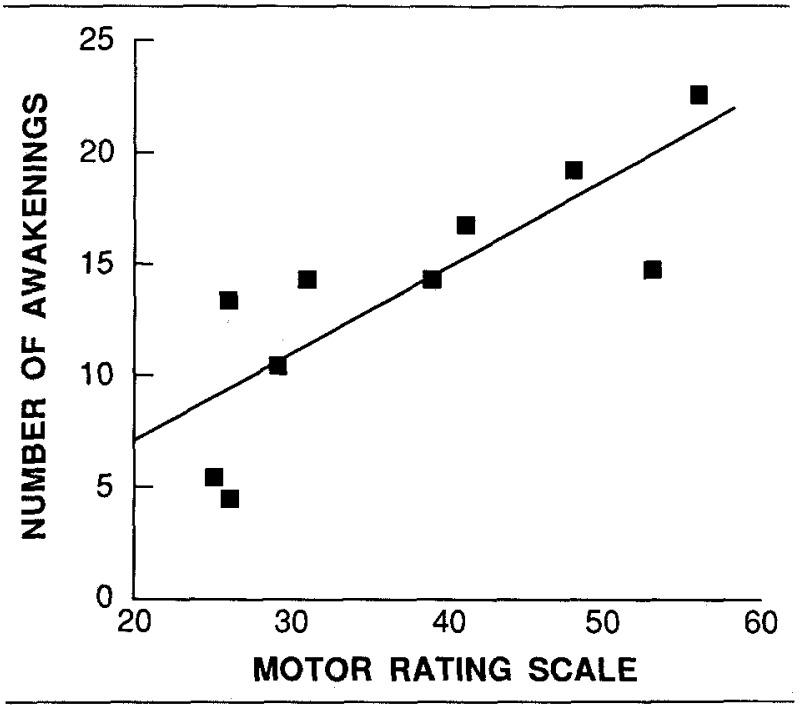

Fig 2. Number of awakenings of duration of 2 minutes or longer per night plotted against Motor Rating Scale $(\mathrm{r}=.82 ; \mathrm{p}=$ $0.004)$.

increasing motor abnormalities. This increase was most likely due to increased amounts of slow electroencephalographic activity in severely affected patients. Although none of the patients were clinically depressed, Profile of Moods score correlated positively with the number of REM periods.

\section{Discussion}

Our findings suggest that insomnia in PSP is of moderate severity early in the disease course and is often associated with delayed sleep onset. As the disease progresses, sleep latency shortens, while insomnia becomes more severe and is associated more with sleep fragmentation than with delayed sleep onset or with early morning awakening. The insomnia associated with PSP therefore differs from psychophysiological insomnia, in which difficulty falling asleep is a promi- 
nent complaint, and from depressive insomnia, which is characterized by early morning awakening. The findings of reduced amounts of REM sleep and decreased numbers of spindles were similar to those in previous reports [1-3].

Our data are consistent with the hypothesis that PSP insomnia is due to altered brain function from neuronal loss in brain regions involved in sleep regulation. Pathological examinations of patients with PSP have shown degenerative changes in several brainstem structures presumed to be involved in sleep regulation, including the locus ceruleus, periaqueductal gray matter, and pontine tegmentum [13]. Although the specific mechanisms that are responsible for sleep maintenance are not understood, the pons, midbrain, and basal forebrain are probably involved, and degenerative changes in these brain regions could cause sleep fragmentation. Pons and midbrain atrophy on computed tomography has been found to correlate with clinical impairment [14]. Furthermore, dopaminergic and cholinergic systems, both of which play a role in the regulation of sleep and REM sleep, are impaired in this disease $[15,16]$. Cholinergic neurons of the pedunculopontine nucleus, which may be involved in the activation of REM sleep [17], are markedly reduced in number in PSP [18].

It is possible that insomnia in our subjects was due to factors associated with disease severity such as discomfort, impaired mobility, or nocturnal disorientation, rather than to neuropathological changes. We did not monitor naps in the subjects, and it is possible that frequent or prolonged daytime naps contributed to nocturnal sleep disturbance. Although these factors may have contributed to insomnia and sleep disruption, the severity of sleep disturbance we observed was greater than that observed in other neurological diseases associated with dementia and impaired mobility. Increased nocturnal wakefulness and frequent awakenings occur in Parkinson's disease $\{19,20\}$, Alzheimer's disease [21, 22], and ischemic stroke [23]. However, in these conditions, nocturnal wakefulness typically constitutes 20 to $40 \%$ of time in bed, rather than the $50 \%$ we observed with PSP. We did not find evidence that sleep apnea, periodic leg movements, or depression-three common causes of sleep fragmentationwere major contributors to the sleep disturbance in most of our subjects.

If PSP insomnia is caused by degenerative neuropathological changes, additional studies that correlate sleep disturbance with specific areas of brain dysfunction, as defined by imaging or neuropathological studies, may help to determine the areas of the brain that are involved in sleep maintenance.

Presented in part at the American Sleep Disorders Association Annual Meeting, June 1988, San Diego, CA.

\section{References}

1. Gross RA, Spehlman R, Daniels JC. Sleep disturbances in progressive supranuclear palsy. Electroencephalogr Clin Neurophysiol 1978;45:16-25

2. Leygonie F, Thomas J, Degos JD, et al. Troubles du sommeil dans la maladie de Steele-Richardson. Etude polygraphique de 3 cas. Rev Neurol (Paris) 1976;2:125-136

3. Perret JL, Jouvet M. Etude du sommeil dans la paralysie supranucleaire progressive. Electroencephalogr Clin Neurophysiol 1980;49:323-329

4. Foster NL, Aldrich MS, Bluemlein L, et al. Failure of cholinergic agonist RS-86 to improve cognition and movement in PSP despite effects on sleep. Neurology (in press)

5. Diagnostic and statistical manual of mental disorders. 3rd ed, revised. Washington, DC: American Psychiatric Association, 1987

6. Rechtschaffen A, Kales A. A manual of standardized terminology, techniques, and scoring system for sleep stages of human subjects. Los Angeles: Brain Information Service/Brain Research Institute, 1968

7. Folstein MF, Folstein SE, McHugh PR: Mini-mental state: a practical method for grading the cognitive state of patients for the clinician. J Psychiatr Res 1975;12:189-198

8. Buschke H, Fuld PA. Evaluation of storage, retention and retrieval in disordered memory and learning. Neurology 1974;24: 1010-1025

9. Goodglass H, Kaplan E. The assessment of aphasia and related disorders. 2nd ed. Philadelphia: Lea \& Febiger, 1983

10. McNair DM, Lorr M, Droppleman LF. Profile of mood states. San Diego: Educational and Industrial Testing Service, 1971

11. Benton AL, Hamsherk DS. Multilingual aphasia examination, revised ed. Iowa City: University of Iowa, 1978

12. Williams RL, Karacan I, Hursch CJ. Electroencephalography (EEG) of human sleep: clinical applications. New York: Wiley, 1974:61

13. Steele JC, Richardson JC, Olszewski J. Progressive supranuclear palsy. Arch Neurol 1964;10:333-359

14. Schonfeld SM, Golbe LI, Sage JI, et al. Computed tomographic findings in progressive supranuclear palsy: correlation with clinical grade. Movement Disorders 1987;2:263-278

15. Kish SJ, Chang LJ, Mirchandani L, et al. Progressive supranuclear palsy: relationship between extrapyramidal disturbances, dementia, and brain neurotransmitter markers. Ann Neurol 1985;18:530-536

16. Ruberg MF, Javoy-Agid F, Hirsch E, et al. Dopaminergic and cholinergic lesions in progressive supranuclear palsy. Ann Neurol 1985;18:523-529

17. Shiromani PJ, Armstrong DM, Berkowitz A, et al. Distribution of choline acetyltransferase immunoreactive somata in the feline brainstem: implications for REM sleep generation. Sleep $1988 ; 1: 1-16$

18. Zweig RM, Whitehouse PJ, Casanova MF, et al. Loss of pedunculopontine neurons in progressive supranuclear palsy. Ann Neurol 1987;22:18-25

19. Friedman A. Sleep pattern in Parkinson's disease. Acta Med Pol 1980;21:193-199

20. Kales A, Ansel RD, Markham CH, et al. Sleep in patients with Parkinson's disease and normal subjects prior to and following levodopa administration. Clin Pharmacol Ther 1971;12:397406

21. Martin PR, Loewenstein RJ, Kaye WH, et al. Sleep EEG in Korsakoff's psychosis and Alzheimer's disease. Neurology 1986;36:411-414

22. Prinz PN, Halter JB. Sleep disturbances in the elderly: neurohormonal correlates. In: Chase $\mathrm{MH}$, Weitzman ED, eds. Sleep disorders. Basic and clinical research. New York: Spectrum Publications, 1983:463-488

23. Korner E, Flooh E, Reinhart B, et al. Sleep alterations in ischemic stroke. Eur Neurol 1986;25:104-110 